\title{
A Citation Analysis Study of Library Science: Who Cites Librarians?
}

\section{Terry Meyer and John Spencer}

\begin{abstract}
Are librarians the only ones who read and cite articles published in library science journals? Research reported here shows that disciplines citing library science articles include computer science, medicine, psychology, the social sciences, and general sciences. This study's methodology involved using Social SciSearch on DIALOG to analyze citations to twenty-four library science journals over a twenty-year period. The authors identified the nonlibrary science fields or disciplines that cited articles published in the library journals included in this study by using the journal subject categories on DIALOG. Although citations from other fields are higher than previous studies indicate, comparison with other fields in the social sciences shows that library science is not commanding citations at the level of the more developed fields.
\end{abstract}

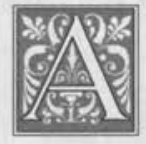

lthough library science has developed a body of professional and scholarly literature in the United States over the past century, librarianship is primarily considered an applied discipline. Even though the work of many librarians brings them regularly in contact with other disciplines, the reverse is not true. Other disciplines do not often refer to library science in their literature, and library science is often considered an insular field that has had limited impact on the development of other disciplines. To explore whether scholars outside the field of library science cite articles from library science journals, this study presents research data that use citation analysis to identify which fields cite the literature of library and information science. Our primary research question is: Do scholars from other fields read, discuss, and cite library literature?

\section{Literature Review}

Researchers such as Robert Grover, Jack Glasier, and Maurice Tsai, who found little theoretical development and analysis in library literature, believe that the field of library and information science is relatively young in comparison with other fields. ${ }^{1}$ They base their assessment on the observation that the field lacks articles which emphasize theoretical analysis and that research in library and information science is very pragmatic and narrow in focus, with little attempt to generalize the results to a broader theoretical context. They concluded that the level of theoretical research in library and information science is at the substantive level primarily, as researchers have less interest in stating formal theories for verification through more rigorous research methodology. ${ }^{2}$

Other researchers have analyzed the characteristics of the literature of library

Terry Meyer is a Librarian at Portland Community College, Oregon, e-mail: tmeyer@zeus.cc.pcc.edu; John Spencer is Reference Coordinator at Arizona State University West in Phoenix, e-mail: j.spencer@asu.edu. 
and information science. For example, Christine E. Thompson used citation analysis to compare the literature of information science and the literature of library science against three norms: 1) the research front index, 2) number of journal citations, and 3) number of citations per article in order to detect any differences that might exist between the two subsets of literature. ${ }^{3}$ Thompson found that the discipline could be considered a "medium" science, and of the two subsets, information science would be more of a "hard" science than library science literature when measured against an index developed by Derek de Solla Price. ${ }^{4}$ Thompson recommended that further study is needed before drawing any conclusions regarding the differences in the two subsets.

When looking at the amount of scholarly exchange between library science and other fields, researchers have discovered a limited impact. For example, Ronald E. Rice and Gregory A. Crawford, in reviewing the scholarship cited by library science articles and communication articles, found that library and information science cites far more communication articles than vice versa. ${ }^{5}$ They found that there is only a small amount of exchange of research on specific topics between the disciplines of communication and library and information science. The authors and articles that "cross the formal boundaries of these two disciplines are concerned primarily, though not exclusively, with more pragmatic issues centered around telecommunications policy, research and theory on computer-mediated communication systems and general bibliometric analyses of program disciplinary evaluation." 6

Other research raised concerns about the pattern of self-citation within the field. In looking at the characteristics of the journal literature of bibliographic instruction, James K. Bracken and John Mark Tucker found that about 74 percent of the citations in articles on bibliographic in- struction referred to sources in the field of library science, while about 26 percent cited sources outside the field. ${ }^{7}$ Comparing their results to other research efforts reinforced their opinion that library literature is prone to self-citation. Likewise, Jeffrey N. Gatten's study of interdisciplinary research paradigms in sociology and library science concluded that a research discipline (e.g., sociology) and an applied discipline (e.g., library science) do not share an interdisciplinary paradigm even when addressing the sociological aspect of libraries in journal articles. ${ }^{8}$ Gatten determined that researchers in library science demonstrated "a strong tendency to cite library science's own body of literature" and that research reported in the library science literature does not often cite relevant research from other disciplines. ${ }^{9}$

Some researchers used citation analysis to understand the developmental stage of a discipline, that is, to clarify whether a field is more or less influential than other fields. One researcher, Clement Y. K. So, employed data from the Journal Citation Reports of the Social Science Citation Index and identified characteristics of eleven social science fields, including information science. ${ }^{10}$ When looking at their impact on other fields, So concluded that both information and library science and communication are young and less influential fields. Information/ library science has the lowest other-field affinity factor of .08 while the more developed fields usually have an other-field affinity of about .25, meaning that onefourth of the citations they command are

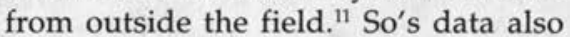
show that information science has the lowest number of citations per article, which So concludes is related to the applied character of the field, compared with fields such as sociology and psychology which are more theoretical or "scholarly" in orientation. ${ }^{12}$

However, this study is constructed to look more broadly at the impact that in- 
formation and library science has on other disciplines. In this study, the authors use the terms information and library science interchangeably. Useful methods for distinguishing between the two subfields do not exist, and there is substantial overlap in the definitions for them. From previous research, such as those examples mentioned in the literature review, the authors know that librarians who publish in library science journals tend to cite library literature. But what about scholars in other disciplines? Do they cite relevant library literature in their references? Researchers are apt to point out that further studies are needed to inform the profession on the "intellectual isolation" that is apparent to many who have studied the discipline. This study is an attempt to determine what kind of impact library and information science articles have on scholars from other disciplines who are publishing in journals of other fields. The research goal of this study is to clarify and understand the extent to which authors in other fields cite articles published in library and information science journals. In which other fields do scholars cite articles published in library science journals?

\section{Methodology}

\section{Data Source}

This study used data from Social SciSearch on DIALOG, which included over twenty years of citation analysis (1972-1994). In addition to producing the citation indices annually, the Institute for Scientific Information (ISI) also produces the Journal Citation Reports (JCR), which includes a number of citation measures developed by ISI. One such analysis is called the impact factor, "a measure of the frequency with which the 'average article' in a journal has been cited in a particular year." ${ }^{13}$ Basically a ratio between the number of citations and the number of articles published, the impact factor for a specific journal is calculated by dividing the number of citations to that journal's articles for the past two years by the number of articles published in those two years. The twenty-four journals the authors selected for this study were listed in the 1992 JCR under the subject category "Information Science and Library Science," and included those journals with an impact factor of .4 or higher.

By expanding on the "cited-works" field, the authors identified varying forms of the journal title abbreviations and placed them in a set. The DIALOG database allows for searching according to

The research goal of this study is to clarify and understand the extent to which authors in other fields cite articles published in library and information science journals.

journal subject category $(\mathrm{SC}=$ information science and library science). ISI assigns a journal subject category to each of the source journals indexed in Social SciSearch. Some journals have more than one journal subject category. To find the number of times a field other than information and library science cited a journal article required a DIALOG search of several steps for each journal. For each journal title, the method for gathering the data from DIALOG was as follows below.

First, the authors identified the source journal articles in Social SciSearch on DIALOG that had the subject category "Information Science and Library Science." They identified over 85,000 articles with the information science and library science subject category. Second, they used the Expand command for journal titles in the cited-works field. This ensured that they used a set of as many cited works as possible for each journal title. Next, the authors removed all the cited works that were in the field of library science. They did this by removing all the articles whose journal subject category was "Information Science and Library 


\begin{tabular}{|lccc|}
\hline \multicolumn{4}{c}{$\begin{array}{c}\text { TABLE 1 } \\
\text { Journal Citation Analysis }\end{array}$} \\
\hline \hline & & & \\
Journal Title & JCR Impact & Ulrich's & Non-LS cites/ \\
Factor & Circulation & LS cites \\
\hline Ann. Rev. Info. Sci. \& Tech. & 1.53 & N/A & $28 / 225$ \\
Bull. of Med. Lib. Assoc. & .48 & 6,300 & $89 / 554$ \\
C\&RL & 1.47 & 13,000 & $45 / 989$ \\
Database Journal & .53 & 4,500 & $105 / 662$ \\
Info. Processing \& Management & .80 & 1,500 & $142 / 621$ \\
Info. Tech. \& Libraries & .43 & 6,800 & $14 / 238$ \\
International Classification & .57 & 2,000 & $13 / 161$ \\
Interlending \& Doc. Supply & .50 & 1,200 & $7 / 58$ \\
Journ. of Acad. Libr. & .58 & 3,000 & $22 / 570$ \\
Journ. of Amer. Soc. for Info. Sci. & 1.007 & 5,800 & $409 / 1,473$ \\
Journ. of Documentation & 1.00 & 3,500 & $159 / 974$ \\
Journ. of Info. Sci. & .49 & 3,500 & $104 / 562$ \\
Lib. Acquis.: Pract. \& Thoery & .85 & 5,300 & $1 / 109$ \\
Library \& Info. Sci. & 1.71 & 1,750 & $1 / 7$ \\
Lib. \& Info. Sci. Research & .55 & 650 & $18 / 230$ \\
Library Journal & .57 & 24,000 & $59 / 1,245$ \\
Library Quarterly & .77 & 2,600 & $16 / 207$ \\
Lib. Res. \& Tech. Services & 1.27 & 9,600 & $1 / 253$ \\
Online Review & .56 & 5,500 & $91 / 1,110$ \\
Program: Auto. Lib. \& Info. Sys. & .41 & 1,000 & $4 / 118$ \\
RQ & .48 & 7,100 & $33 / 1,047$ \\
Scientometrics & .63 & N/A & $496 / 760$ \\
Serials Librarian & .82 & 1,500 & $14 / 194$ \\
Telecommunications Policy & .43 & N/A & $60 / 80$ \\
& & & $1,931 / 12,447$ \\
\hline
\end{tabular}

Science." The authors were left with a set of articles cited by authors in disciplines other than library and information science. Finally, they ranked the remaining citations by journal subject categories using the Rank command on DIALOG, thus providing a listing of subject categories and the number of citations within each subject. As a sampling technique, this methodology provides the subject category for those citations that are not in the field of information and library science. ${ }^{14}$

\section{Results}

The data collection (see table 1) resulted in an analysis of 14,378 citations that ref- erenced articles published in the twentyfour journal titles selected for this study. Of these citations, $12,447(86.6 \%)$ appeared in library and information science journals, while 1,931 citations (13.4\%) appeared as references in articles in journals from other fields. The authors' primary interest in this study is to clarify which fields are represented by the citations (13.4\%) from nonlibrary science journals.

Analysis of the fields that cited articles in the library and information science journals showed that the journals used in this study represented ninety-four distinct subject categories. Four subject categories had over one hundred citations: (1) computer applications and cybernet- 
ics, (2) education and educational research, (3) ergonomics, and (4) psychology. Nine subject categories had between fifty and one hundred citations each: (1) business, (2) chemistry, (3) communication, (4) management, (5) medicine, (6) physics, (7) planning and development, (8) social science (interdisciplinary), and (9) sociology. The authors created four additional subject categories by analyzing and combining subject categories: (1) arts and humanities, (2) economics, (3) engineering/mathematics, and (4) general science. Twenty subject categories had between ten and fifty citations, and the remaining sixty-two subject categories had fewer than ten citations. Twenty subject categories had only one citation. They combined the journal subject categories where it was appropriate and consolidated them under broader subject categories.

Figure 1 shows the journal subject categories with a bar graph representing the number of citations for each journal subject category. The chart includes the percentage of total citations in parentheses at the end of each bar graph. Computer applications and cybernetics journals have the highest percentage $(15.5 \%)$ of citations to the twenty-four library science journals, with social science journals next (11.6\%), followed by medicine $(10.2 \%)$, psychology $(9.9 \%)$, and general science $(9.9 \%)$ We cannot determine from our study exactly why scholars in these fields cite library and information science journal articles, but these fields are linked in some way to library and information science.

Figure 2 illustrates which journals in library and information science were cited by nonlibrary science fields. Two journals stand out: Scientometrics and the Journal of the American Society for Information Science. Between the two of them, they received 44.9 percent of the citations from nonlibrary science fields. Scientometrics ranks first in terms of the number of citations from other fields $(23.3 \%)$. Scientometrics, published in Amsterdam, is defined in Ulrich's as "an international journal for all quantitative aspects of the science of science, communication in science and science policy." 15 In reviewing the tables of contents over the past two years, most articles in Scientometrics are about science publishing, primarily concerning topics related to how scientists communicate and how scientific information is distributed. The Journal of the American Society for Information Science ranks second in terms of citations from others fields, primarily computers, engineering, ergonomics, general science, medicine, psychology and the social sciences. Defined in Ulrich's as "a forum for discussion and experimentation in the theory and practice of communicating information," this journal features articles on operations research, automation applications, communications, and computer technology. ${ }^{16}$ Other journals that received

\section{Three journals received about five percent each of all the citations from nonlibrary science journals: Bulletin of the Medical Library Association, Online, and the Journal of Informa- tion Science.}

a significant number of citations from nonlibrary science fields include: Information Processing Management (8.6\%), The Journal of Documentation (8\%), and Database $(6.2 \%)$. Three journals received about five percent each of all the citations from nonlibrary science journals: Bulletin of the Medical Library Association, Online, and the Journal of Information Science. The other sixteen journals in this study received a total of 18.3 percent of the citations from nonlibrary science fields, with no journal receiving more than 3.3 percent of the nonlibrary science citations.

Table 2 indicates the journal subject categories that cited the twenty-four library and information science journals, along with the actual number of citations to each journal. For example, journals in fields such as the social and general sciences, 
FIGURE 1

Fields Citing Library Science Journals

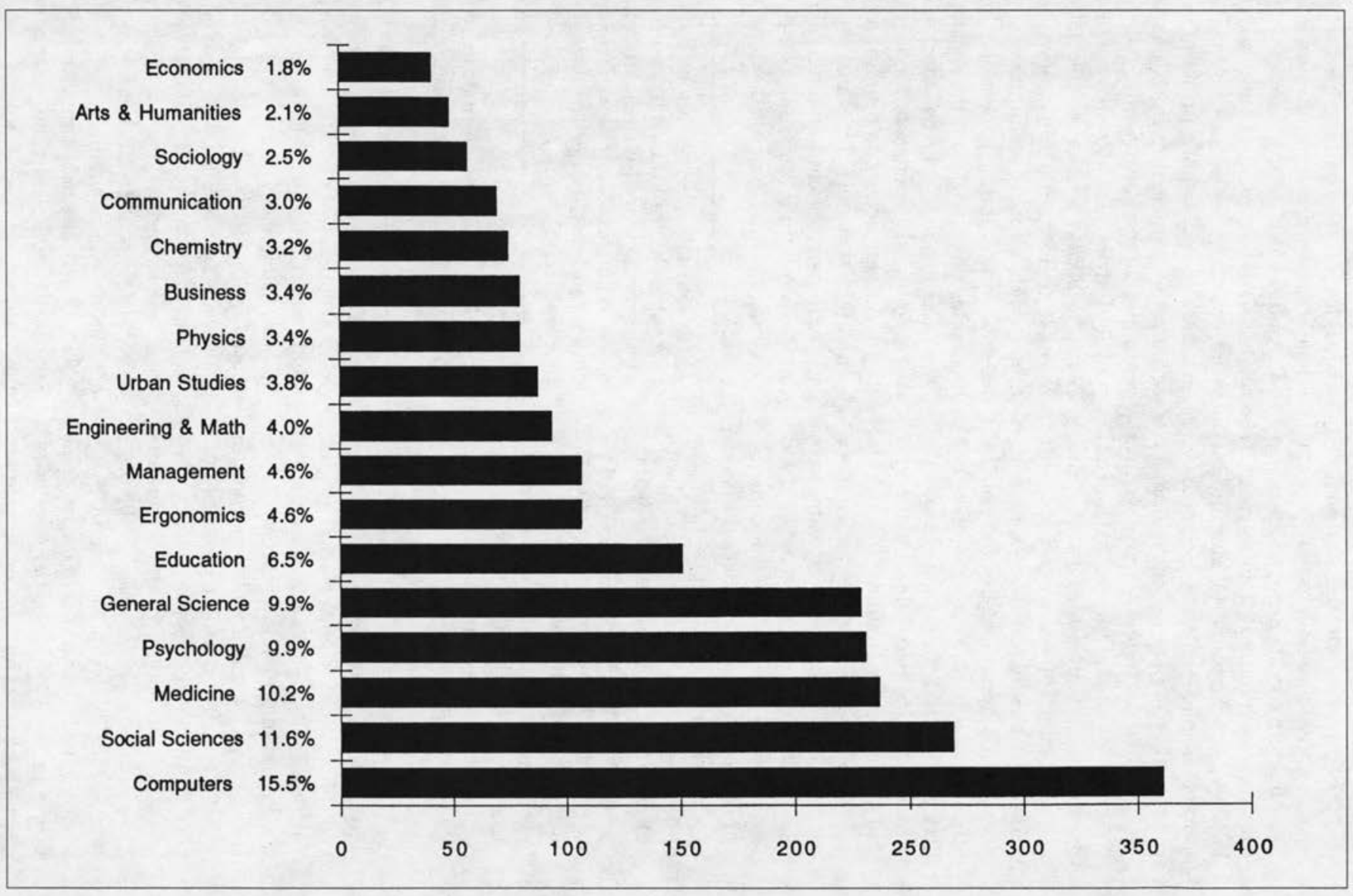


FIGURE 2

Library Science Journals Cited by Nonlibrary Science Fields

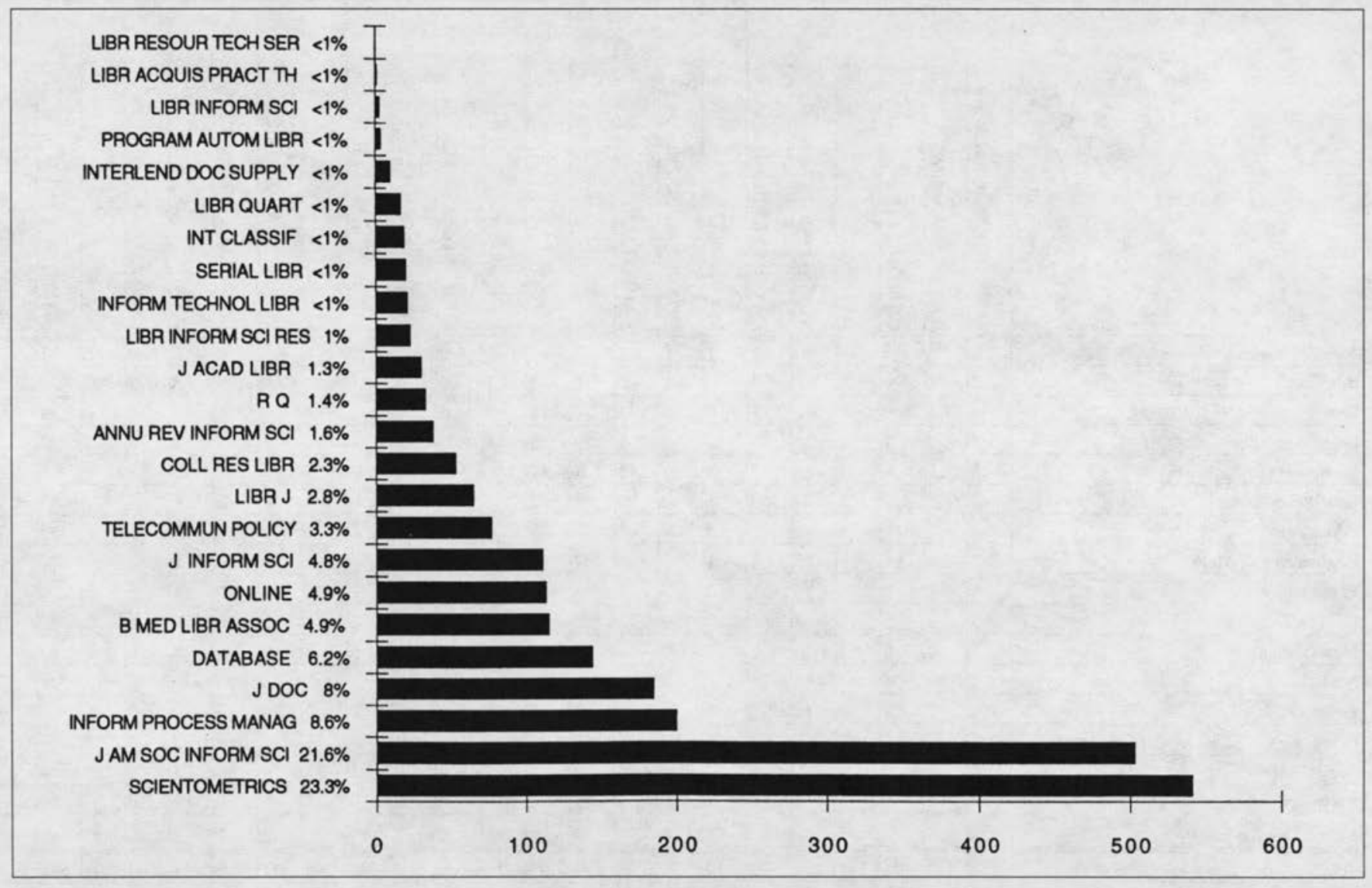


TABLE 2

Citations from Nonlibrary Fields to Library Science Fields

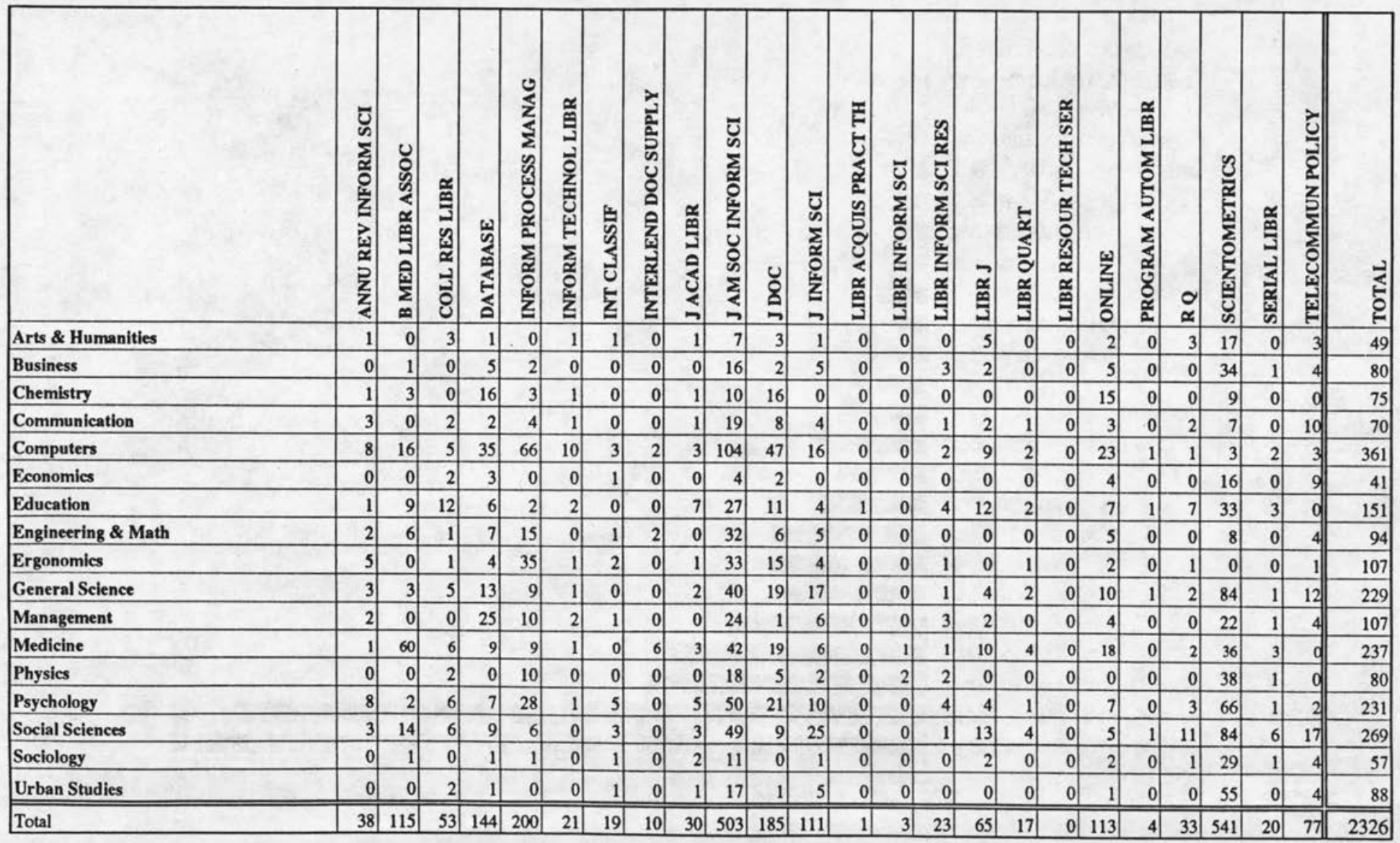


psychology, and urban studies published articles that cited Scientometrics more often than any other journal in our sample. The second highest cited journal, the Journal of the American Society for Information Science, had citations in journals from the fields of computers, engineering, ergonomics, general science, medicine, psychology, and the social sciences. Two journals that feature articles on computers in libraries, Online and Database, are also heavily cited journals. The two journals that have the highest circulation, College \& Research Libraries (circulation 13,000) and Library Journal (circulation 24,000), were not cited as often.

Nonlibrary science fields also cited other journals to a significant extent. Computer and ergonomics journals had articles that cited Information Processing Management, and computer and psychology journal articles cited the Journal of Documentation. The highest number of citations to articles in Database were from computer journals (24\%), with citations from management journals second (17\%). The Bulletin of the Medical Library Association had a significant number of citations from journals in the medical field. Computer science $(20 \%)$, medicine $(16 \%)$, and chemistry $(13 \%)$ cited articles published in Online more than other fields.

In analyzing the citations from key fields to library science journal articles, the authors found certain journals cited significantly more than others. For example, table 2 shows that computer journals cited articles in the Journal of the American Society for Information Science (28.8\%), Information Processing Management (18.2\%), and the Journal of Documentation (13\%). Journals in the social sciences cited articles in Scientometrics (31\%), the Journal of the American Society for Information Science (18.2\%), and the Journal of Information Science (9.2\%). Medical journals cited articles in the Bulletin of the Medical Library Association (25.3\%), the Journal of the American Society for Information Science (17.7\%), and Scientometrics (15.1\%).

\section{Discussion}

Analysis of the citations to the twentyfour journals revealed that other fields cited articles in two journals, Scientometrics $(23.3 \%)$ and the Journal of the American Society for Information Science (21.6\%), almost as many times as the rest of the journals in this study. However, eliminating the two journals from table 2 would not significantly alter the ranking of the fields that cited library science journal articles. Conversely, eliminating the two highest-ranked journals would significantly diminish the number of citations to library and information science journals from nonlibrary science fields. These two journals received the major portion of the citations from nonlibrary science journals (44.9\%).

In analyzing which nonlibrary science fields cite library science, clearly computer journals $(15.5 \%)$ are in the lead, and social science journals (11.6\%) are second, followed by a cluster of three fieldsmedicine $(10.2 \%)$, psychology $(9.9 \%)$, and general science journals $(9.9 \%)$. Other fields that cite articles in library science journals to a lesser extent are education, ergonomics, and management. The links between library and information science and the fields of computer science, the social sciences, medicine, and psychology are not apparent from this study. Additional research is needed to clarify what types of citations are made to library and information science journal articles.

\section{Conclusion}

From analysis of the data collected, the authors conclude that information and library science is commanding citations from a wide range of fields, but primarily from five fields: computers, the social sciences, medicine, psychology, and the general sciences. Approximately 13 percent of the citations to articles in library science journals come from articles published in nonlibrary science journals. In comparison to the research Clement So published in 1988, library and informa- 
tion science has increased the level of its citations from other fields. So concluded that library and information science commands 8 percent of its citations from other fields. ${ }^{17}$ Although the increase is important to consider, library and information science has not yet surpassed the next lowest field in So's study, language/linguistics, which commanded 15 percent of its citations from other fields. ${ }^{18}$ The highest field in So's analysis is sociology with 45 percent of its citations from other fields. ${ }^{19}$ The increase from 8 to 13 percent over a period of time may indicate that the field is maturing and increasing its other-field affinity. Nevertheless, the field has a long way to go if library science is

\section{Specifically, research is needed to determine exactly what types of articles published in library science journals are being cited.}

to become a more influential field and command one-quarter of its citations from other fields, as So found of the more developed fields. ${ }^{20}$

Possibilities in terms of the development of the field of library and information science are important to consider. Specifically, research is needed to determine exactly what types of articles published in library science journals are being cited. Many library journals publish articles that are written about professional experiences and programs, for example, the "how to do it" article. ${ }^{21}$ Researchers need to ask if this type of article decreases the likelihood of citations from other fields. Additionally, librarians rarely publish articles framed in a theoretical perspective that are considered more generalizable research articles. Researchers need to find out whether this means that library science publications are less likely to be cited by other fields, particularly those fields that have a strong theoretical base, such as psychology. Generally, psychology is considered the core scholarly field in the social sciences, and other fields draw upon its theoretical development. Research is needed to determine how much library science draws upon the field of psychology and related social sciences.

One purpose of research is "to verify and generate theory for practitioners in the library and information professions," according to Grover, who recommended that textbooks and research methods classes in library and information science need to encourage the examination and verification of relevant theories and methodologies from other disciplines, especially the social sciences. ${ }^{22}$ In order to do this, librarians need to analyze research in other disciplines and incorporate their theoretical frameworks into the research questions for library and information science. By incorporating theoretical perspectives from other fields, librarians may be more likely to share theoretical paradigms with other fields. Furthermore, library and information science scholars should concentrate on building a theoretical foundation for the field. Fields with the strongest theoretical base are cited more often by other fields. However it is accomplished, theory building and integration of theory into research are potential ways to attract attention from other fields and possibly command more citations from other fields as a result. Nevertheless, more research is needed to clarify the link between the nonlibrary science journal articles that cite library science journal articles. What kinds of articles published in library science journals are being cited by other fields? Additional research is needed before any generalizations can be made about how library science can garner additional citations from other fields. 


\section{Notes}

1. Robert Grover, Jack Glasier, and Maurice Tsai, "An Analysis of Library and Information Science Research," Journal of Educational Media \& Library Sciences 28 (spring 1991): 276-78.

2. Ibid., 276.

3. Christine E. Thompson, "Using Citation Analysis to Analyze Library and Information Science Journal Characteristics," College \& Research Libraries News 52 (July/ Aug. 1991): 439-41.

4. Ibid., 439.

5. Ronald E. Rice and Gregory A. Crawford, "Analysis of Citations between Communication and Library and Information Science Articles" in Proceedings of the 55th Annual Meeting, ASIS (Medford, N.J., Learned Information, 1992): 8-12.

6. Ibid., 10.

7. James K. Bracken and John Mark Tucker, "Characteristics of the Journal Literature of Bibliographic Instruction," College \& Research Libraries 50 (Nov. 1989): 665-73.

8. Jeffrey N. Gatten, "Paradigm Restrictions on Interdisciplinary Research into Librarianship," College \& Research Libraries 52 (Nov. 1991): 575-84.

9. Ibid., 583.

10. Clement Y. K. So, "Citation Patterns of Core Communication Journals: An Assessment of the Developmental Status of Communication," Human Communication Research 15 (winter 1988): 236-55.

11. Ibid., 247.

12. Ibid.

13. Institute for Scientific Information, SSCI Journal Citation Reports. Microform. (Philadelphia: Institute for Scientific Information, 1990): 9.

14. In using Social SciSearch on DIALOG (File 7), only those journals that are considered source journals by ISI have been assigned a journal subject category. Some journals are assigned more than one journal subject category when they contain content which crosses disciplines. All journals without a journal subject category are ignored in this study. Likewise, books and dissertations or other types of references are excluded from this study.

15. Ulrich's International Periodical Directory 1994-95 (New Providence, R.I.: Bowker, 1994): 5358.

16. Ibid., 3420 .

17. So, "Citation Patterns of Core Communication Journals," 247.

18. Ibid.

19. Ibid.

20. Ibid.

21. Grover, Glasier, and Tsai, "An Analysis of Library and Information Science Research," 295.

22. Ibid., 296. 


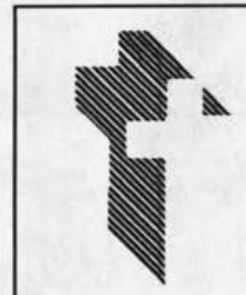

\section{Christian Periodical} INDEX

\section{* Over 90 Titles \\ * Beginning in 1956 \\ * Published \\ Three \\ Times a \\ Year}

Index covers a broad spectrum of knowledge from an evangelical Christian perspective.

\section{AGL}

Association of Christian Librarians

P. O. Box 4 Cedarville, $\mathrm{OH}$ 45314-0004

\section{New From RAND}

A book that will be invaluable to scbolars, diplomats, and policymakers who deal with Oman and its neigbbors

\section{OMAN AND THE WORLD:} The Emergence of an Independent Foreign Policy by Joseph A. Kechichian

This is the first book to systematically analyze the foreign policy of

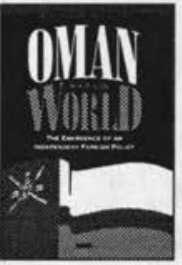
the Sultanate in any language. It is a landmark publication that traces the origins of the 0mani nation-state, identifies trends in 0mani diplomacy, and examines the Sultanate's foreign policy in the modern era.

$\$ 30.00$ paper • ISBN 0-8330-2332-2 400 pp.

Available December 1995 from:

National Book Network Inc. $800-462-6420$ or 301-459-3366

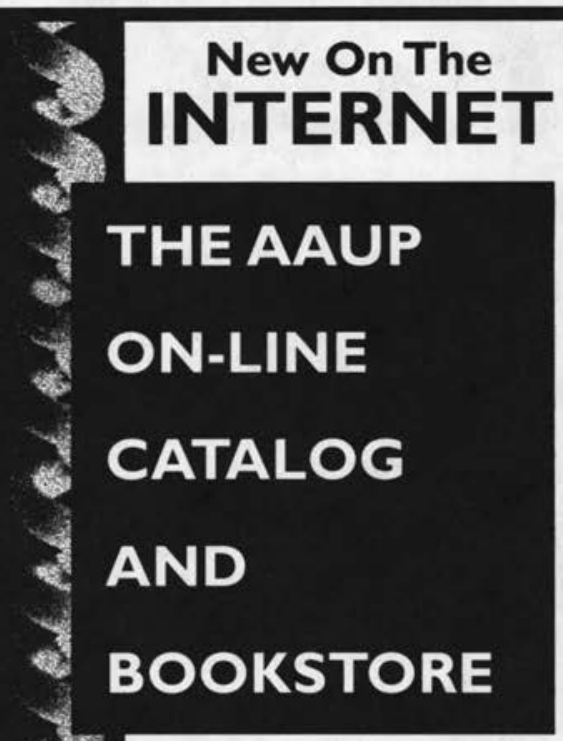

\section{A COMPREHENSIVE ELECTRONIC RESOURCE}

of scholarly publications from the members of the Association of American University Presses

\section{FREE ACCESS}

to bibliographic information on more than 65,000 titles

\section{USER-FRIENDLY PROCEDURES}

using author, title, keywords, subject category, or publisher name

\section{EASY ORDERING INFORMATION}

Using customized order forms from participating presses

The Catalog contains fully searchable bibliographic data and descriptive text from more than 50 scholarly publishers.

Accessing the Catalog via WWW or Gopher: http://aaup.princeton.edu http://press-gopher.uchicago.edu

The Association of American University Presses. Inc 584 Broadway - Suite 410 - New York, NY 10012 